\title{
Pemanfaatan Oasis Basah Sebagai Bahan Alternatif Pengganti Media Konvensional Pada Pencangkokan Tanaman Mangga (Mangifera indica, L) di Laboratorium Tanaman
}

\author{
Ujang Tri Cahyono', Muh. Hasan ${ }^{2}$ \\ ${ }^{1}$ Laboratorium tanaman, Jurusan Produksi Pertanian \\ ${ }^{2}$ Laboratorium tanaman Jurusan Produksi Pertanian \\ Politeknik Negeri Jember, Jalan Mastrip Kotak Pos 164 Jember 68101 \\ ujang.tri.cahyono.polije@gmail.com
}

\begin{abstract}
ABSTRAK
Salah satu kegiatan laboratorium tanaman adalah untuk meneliti mengenai pengelolaan tanaman hortikultura agar didapatkan tanaman yang bersifat unggul dan cepat berproduksi. Ketersediaan bibit berkualitas merupakan salah satu kendala dalam meningkatkan hasil dan kualitas buah mangga. Dalam hal untuk mendapatkan tanaman mangga yang berproduksi lebih cepat dan menghasilkan buah yang berkualitas serupa dengan tanaman induknya. Maka perbanyakan vegetatif melalui cangkok merupakan salah satu alternatifnya. Mencangkok merupakan salah satu teknik perbanyakan vegetatif dengan cara pelukaan atau pengeratan cabang pohon induk dan dibungkus media tanam untuk merangsang pembentukan akar. Penelitian ini bertujuan untuk mengetahui persentase keberhasilan pencangkokan tanaman mangga menggunakan media oasis basah, mengetahui efektifitas penggunaan oasis basah sebagai pengganti media konvensional. Penelitian ini terdiri dari 2 perlakuan dengan jumlah 15 cangkokan pada masing-masing perlakuan, sehingga didapatkan jumlah populasi 30 cangkokan. Perlakuan terdiri dari: $\left(C_{o}\right)$ perlakuan cangkok dengan menggunakan media konvensional; $\left(C_{1}\right)$ perlakuan cangkok dengan menggunakan media oasis basah. Hasil penelitian menunjukkan bahwa persentase keberhasilan cangkokan tanaman mangga menggunakan media oasis basah sama dengan penggunaan media konvensional. Kajian ini dapat memberikan sebuah solusi alternatif bahwa media oasis basah dapat dijadikan sebagai bahan pengganti media konvensional dalam kegiatan praktikum pencangkokan tanaman.
\end{abstract}

Kata kunci : oasis basah, media konvensional, pencangkokan, tanaman mangga

\section{PENDAHULUAN}

Laboratorium Tanaman merupakan sarana bagi mahasiswa, pranata laboratorium (PLP) dan dosen dalam melakukan kegiatan pendidikan, penelitian, dan pengabdian kepada masyarakat. Salah satu kegiatan di laboratorium tanaman adalah untuk meneliti mengenai pengelolaan tanaman hortikultura agar didapatkan tanaman yang bersifat unggul dan cepat berproduksi. Mangga (Mangifera indica, L) merupakan salah satu komoditas tanaman hortikultura penghasil buah yang prospektif dikembangkan untuk memenuhi kebutuhan dalam negeri dan memiliki peluang tinggi sebagai komoditas ekspor. Namun Sampai saat produksi mangga dalam negeri masih rendah karena kebanyakan masyarakat masih menggunakan bibit yang berasal dari biji sehingga memerlukan waktu lama dalam menghasilkan buah dan hasil serta kualitas buahnya pun beragam dan seringkali lebih rendah kualitas serta kuantitasnya dibandingkan tanaman indukannya (Astutik, 2008). 
Ketersediaan bibit berkualitas merupakan salah satu kendala dalam meningkatkan hasil dan kualitas buah mangga. Agar bisa mendapatkan tanaman mangga yang berproduksi lebih cepat daripada tanaman yang berasal dari biji dan buah yang dihasilkan serupa dengan tanaman induknya, maka perbanyakan vegetatif melalui cangkok merupakan salah satu alternatifnya. Mencangkok merupakan salah satu teknik perbanyakan vegetatif dengan cara pelukaan atau pengeratan cabang pohon induk dan dibungkus media tanam untuk merangsang terbentuknya akar. Dalam hal kegiatan mencangkok akar akan tumbuh ketika cabang yang dicangkok masih berada padai pohon induknya (Prameswari et al. 2014).

Keberhasilan dalam kegitan pencangkokan tanaman mangga dipengaruhi oleh banyak faktor antara lain ukuran (umur) batang dan sifat media tanaman. Pemilihan diameter batang yang ideal, akan membentuk perakaran yang lebih banyak, hal ini karena permukaan bidang perakaran yang lebih luas akan tetapi umur batang sebaiknya tidak terlalu tua (berwarna coklat atau coklat muda). Sifat media tanam haruslah yang mampu menyerap banyak air, tidak becek, mampu menahan air meskipun terkena angin dan panas matahari (Kuswandi, 2013).

Media konvensional yang sering digunakan masyarakat saat ini adalah tanah lapisan atas yang cukup mengandung unsur hara. Meskipun tanah mampu menyerap air dan menahan air tetapi seringkali terlalu becek, mudah padat dan kurang praktis dalam kegiatan mencangkok, hal ini bisa mempengaruhi keberhasilan dalam kegiatan pencangkokan. Salah satu bahan yang saat ini banyak dimanfaatkan sebagai media tanam, terutama untuk tanaman hias dan bunga adalah oasis basah. Oasis basah yang dijadikan sebagai media tanam berbentuk seperti busa atau spon yang ringan. Meskipun dapat menyerap banyak air, media oasis basah tidak becek karena air disimpan di dalam rongga-rongga media dan air akan dipegang erat, meskipun terken angin ataupun panas matahari. Media oasis basah mempunyai banyak rongga sehingga memungkinkan akar tanaman tumbuh dan berkembang dengan leluasa.

Tujuan dari penelitian ini adalah untuk mengetahui persentase keberhasilan pencangkokan tanaman mangga menggunakan media oasis basah dan mengetahui efektifitas penggunaan oasis basah sebagai pengganti media konvensional pada pencangkokan tanaman mangga.

Hasil penelitian ini diharapkan dapat memberikan atau menambah informasi bagi pembaca guna mencoba penggunaan media oasis basah sebagai bahan alternatif pengganti media konvensional karena lebih praktis dan efisien apa lagi jika dilakukan pencangkokan pada musim kemarau. Sebagai tambahan referensi bagi peneliti berikutnya yang akan melakukan penelitian lanjutan dalam penyempurnaan atau modifikasi media pencangkokan pada tanaman mangga yang lebih efektif dan efisien. Dapat memberikan solusi alternatif bahan pengganti media konvensional yang lebih praktis dan efisien dalam pencangkokan tanaman mangga yang dapat diimplementasikan dalam penyelenggaraan kegiatan praktikum mahasiswa di laboratorium tanaman.

\section{METODE PENELITIAN Waktu dan tempat penelitian}

Penelitian ini dilaksanakan di lahan laboratorium tanaman dengan ketinggian tempat $89 \mathrm{~m}$ di atas permukaan air laut. Jenis tanah inceptisol, pada bulan Maret 2018 sampai dengan bulan Mei 2018.

\section{Bahan dan Alat}

Bahan yang digunakan untuk melaksanakan penelitian ini adalah: tanaman mangga manalagi yang telah berumur 5 tahun dan telah menghasilkan produksi buah dengan kuantitas dan kualitas yang baik, tanah lapisan atas (top soil), plastik transparan vol $1 \mathrm{~kg}$, oasis basah, vitamin B1 liquinox cair, air bersih. 
Alat yang digunakan dalam kegiatan penelitian ini adalah: pisau sayat (pisau okulasi), tali rafia, alat suntikan, gunting pangkas, silet cutter, penggaris mika, bak plastik pemeraman, timba plasik, gergaji kayu, gelas ukur.

\section{Metode Penelitian}

Penelitian ini terdiri dari 2 perlakuan

(C) dengan jumlah 15 cangkokan pada masing-masing perlakuan, sehingga didapatkan jumlah populasi 30 cangkokan:

$\mathrm{C}_{\mathrm{o}}$ : Merupakan perlakuan cangkok dengan menggunakan media konvensional.

$\mathrm{C}_{1}$ : Merupakan perlakuan cangkok dengan menggunakan media oasis basah.

\section{Pelaksanaan Penelitian Persiapan Media Cangkok}

Persiapkan larutan air dan vit B1 liquinox cair dengan perbandingan $1 \mathrm{ml}$ vit B1 liquinox dicampur dengan 5 ltr air bersih 5 dalam bak pemeraman. Kemudian media cangkok oasis basah dipotongpotong dengan ukuran panjang $5 \mathrm{~cm}$, lebar $3 \mathrm{~cm}$, dan tinggi atau tebal $3 \mathrm{~cm}$ dan direndam di dalam larutan pada bak pemeraman selama kurang lebih 20 menit. Media konvensional disiapkan dengan mencari tanah lapisan atas (top soil) di bawah pohon bambu kemudian di taruh dalam timba atau sack, apabila media terlalu kering bisa dibasahi menggunakan air bersih sampai media mencapai kapasitas lapang (tidak lembek atau becek) sehingga mudah dikepal atau dibentuk.

\section{Persiapan Bahan Tanam}

Bahan tanam mangga manalagi yang digunakan untuk indukan adalah tanaman mangga manalagi yang telah berumur 5 tahun dan telah menghasilkan produksi buah dengan kuantitas dan kualitas yang baik. Kemudian menentukan cabang yg akan dicangkok dengan kriteria lurus, cukup besar diperkirakan berdiameter kurang lebih 2-3 cm dan tidak terlalu tua serta masih berwarna hijau atau coklat agar nanti pohon atau cabang cukup kuat utk mandiri.

\section{Kegiatan Pencangkokan}

Pilih cabang yang sehat dan lebih baik tumbuhnya secara vertikal dengan diameter 2-3 cm. Buat irisan melingkar dengan jarak sekitar $10 \mathrm{~cm}$ lalu kupas kulit batang atau cabangnya. Bersihkan lapisan kambium yang menempel pada kayu sampai kesap dan biyarkan beberapa saat supaya hasil sayatan pada cabang mengering. Setelah lapisan kambium bersih, kemudian tutup bagian sayatan tersebut dengan potongan oasis basah yang telah direndam dalam larutan air + vit B1 liquinox cair (perlakuan $\mathrm{C}_{1}$ ) dan tanah top soil yang sudah dibasahi air sampai kapasitas lapang (perlakuan $\mathrm{C}_{0}$ ). Balut bagian yang telah terlapisi atau tertutupi media oasis basah dan tanah top soil dengan plastik transparan vol $1 \mathrm{~kg}$. Ikat balutan tersebut dengan menggunakan tali plastik (tali rafia) dibagian ujung atas dan bawah seperti membungkus permen. Plastik transparan tersebut diberi beberapa lubang kecil sebagai jalan masuknya air dan aerasi media tanam cangkok.Lakukan monitoring secara berkala agar kelembaban cangkokan tetap terjaga, apabila media kering tidak ada hujan sebaiknya dilakukan penyiraman $1 \mathrm{x}$ sehari dengan cara menyuntikkan air menggunakan alat suntikan pada media tanam cangkok untuk tetap menjaga kelembaban cangkokan. Setelah kurang lebih satu bulan, akar akan mulai tumbuh. Jika pertumbuhan akar sudah cukup baik, maka potong cabang bagian bawah cangkokan menggunakan gergaji kayu dan cangkokan siap ditanam di wadah atau tempat baru. 

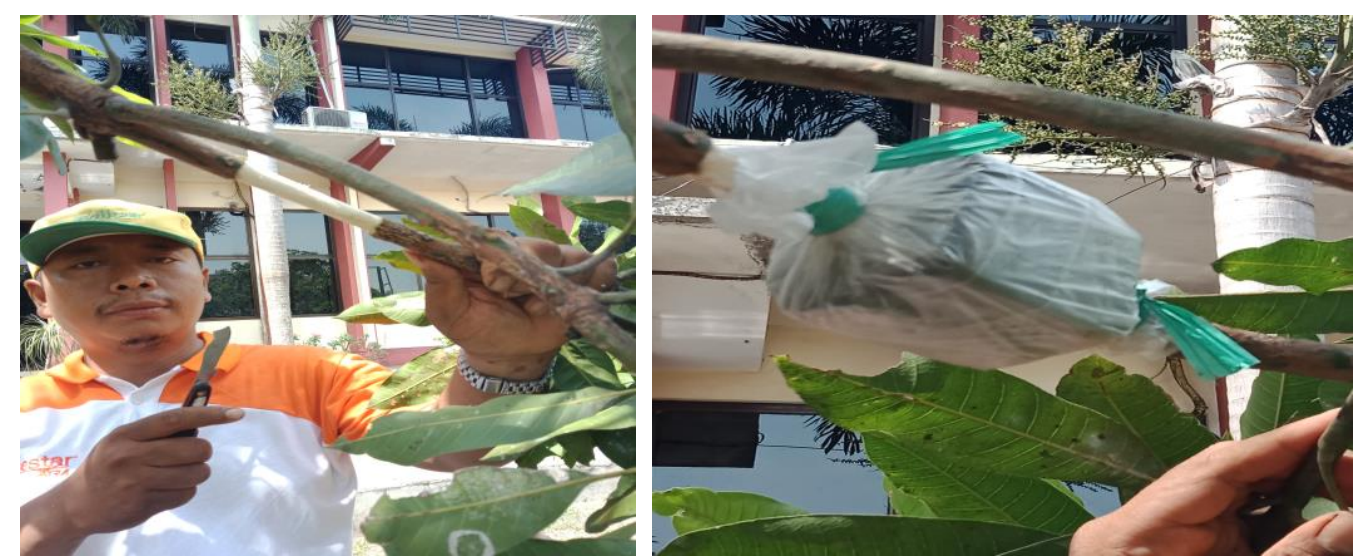

Gambar 1. Penyayatan cabang mangga Gambar 2. Pencangkokan dengan oasis basah
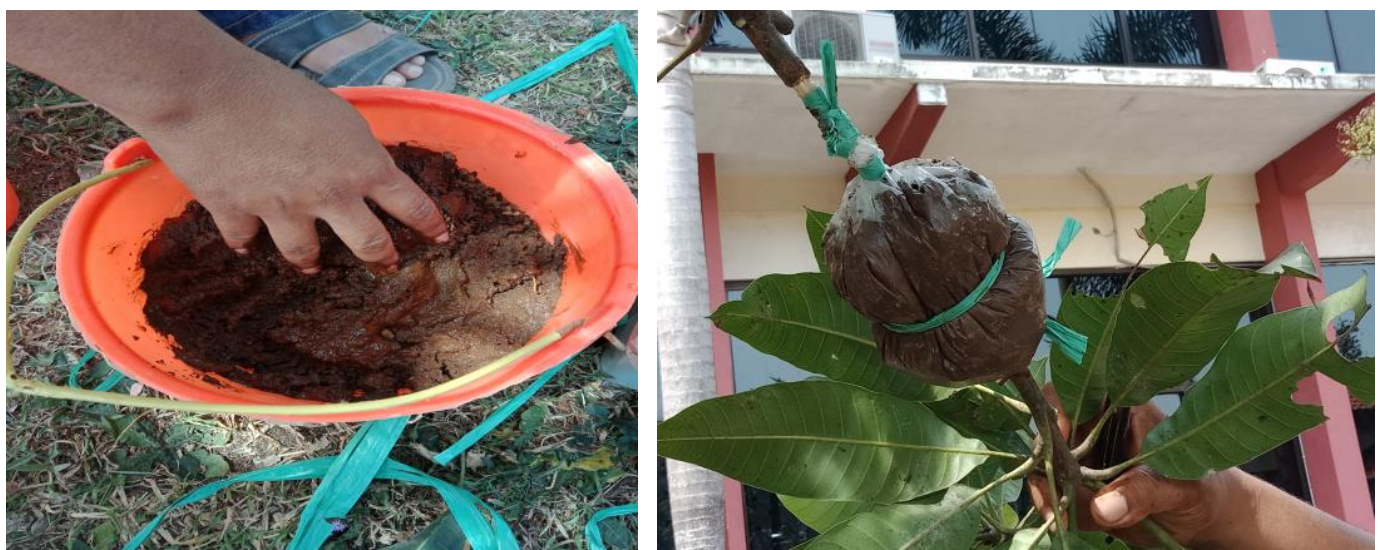

Gambar 3. Persiapan media konvensional Gambar 4. Pencangkokan dengan media kovensional

\section{HASIL DAN PEMBAHASAN}

Hasil pengamatan jumlah dan persentase cangkokan hidup pada tanaman mangga menunjukan bahwa perlakuan cangkok dengan menggunakan media oasis basah $\left(\mathrm{C}_{1}\right)$ mampu menghasilkan jumlah dan persentase cangkokan hidup sedikit lebih baik pada pengamatan bulan 1 (pertama) akan tetapi untuk pengamatan pada bulan ke 2 (dua) antara penggunaan media konvensional $\left(\mathrm{C}_{0}\right)$ dan oasis basah menunjukkan jumlah dan persentase cangkokan hidup yang sama, seperti ditunjukkan pada Tabel 1 .

Tabel 1. Pengamatan Jumlah dan Persentase Cangkokan Hidup pada Bulan ke 1 dan 2

\begin{tabular}{cccccc}
\hline \multirow{2}{*}{ Perlakuan } & \multirow{2}{*}{ Populasi Awal } & \multicolumn{3}{c}{ Waktu dan Persentase Cangkokan Hidup } \\
\cline { 3 - 6 } & & \multicolumn{3}{c}{ Bulan ke 1 } & \multicolumn{3}{c}{ Bulan ke 2 } \\
\cline { 2 - 6 } & 15 & Jml & $\%$ & Jml & $\%$ \\
\hline C0 & 15 & 9 & 53,33 & 13 & 86,67 \\
\hline C1 & 15 & 60 & 13 & 86,67 \\
\hline
\end{tabular}

Tabel 1 menunjukkan bahwa perlakuan cangkok dengan menggunakan media oasis basah $\left(\mathrm{C}_{1}\right)$ mampu menghasilkan cangkokan hidup berjumlah 9 dengan persentase $60 \%$ yang sedikit lebih baik dari pada penggunaan media konvensional dengan jumlah 8 dan persentase $53,33 \%$ pada bulan 1 . Sedangkan pada pengamatan bulan ke 2 diantara kedua perlakuan media menghasilkan jumlah dan persentase 
cangkokan hidup yang sama yaitu dengan jumlah 13 dan persentase 86,67\%.

Berdasarkan hasil penelitian secara keseluruhan antara perlakuan penggunaan media alternatif oasis basah dan media konvensional pada pencangkokan tanaman mangga, keduanya menunjukkan hasil dan persentase keberhasilan yang relatif sama atau tidak menunjukkan perbedaan yang signifikan terhadap tingkat keberhasilan pencangkokan tanaman mangga. Hal ini dikarenakan baik media konvensional maupun media oasis basah sama-sama memiliki kemampuan menyerap dan menyimpan atau mengikat air yang relatif sama sehingga mampu mendorong kalus dapat tumbuh dengan baik dan menyebabkan regenerasi akar menjadi lebih cepat.

Salah satu faktor yang perlu diperhatikan dalam pencangkokan adalah media cangkok. Media yang baik harus mempunyai sifat mudah menyerap air, menahan air dalam waktu lama, kelembabannya tinggi tetapi aerasinya baik dan beratnya ringan. Media cangkok tidak boleh terlalu basah dan tidak mengandung jamur yang dapat menyebabkan kerusakan dan kematian cangkokan (Hendrata dan Sutardi, 2010).

Bahri (1999) menyatakan bahwa, keberadaan air disekitar perakaran tanaman akan mampu merangsang pembentukan dan perkembangan akar secara optimal karena respirasi akar akan berlangsung sempurna. Lebih lanjut dijelaskan bahwa, air penting untuk pertumbuhan akar, terbukti oleh kenyataan bahwa akar tidak tumbuh melalui lapisan-lapisan media tanam yang kering. Kekurangan kelembapan tanah secara signifikan akan menurunkan berat akar dan panjang akar sehingga akan berpengaruh terhadap pertumbuhan dan perkembangan tanaman (Gardner, 1991). Kemampuan media cangkok menahan air lebih banyak di dalam pori-pori dan kelancaran sirkulasi udara di dalam media akan mendorong pertumbuhan primordia akar menjadi lebih cepat (Prameswari et al. 2014).

\section{KESIMPULAN DAN SARAN}

Hasil penelitian ini menunjukkan bahwa perlakuan pencangkokan dengan menggunakan media oasis basah $\left(\mathrm{C}_{1}\right)$ dapat digunakan sebagai alternatif pengganti media pencangkokan konvensional $\left(\mathrm{C}_{\mathrm{o}}\right)$ karena kedua perlakuan media menunjukkan hasil persentase keberhasilan yang relatif sama pada pencangkokan tanaman mangga. Dari kajian secara empiris ini dapat memberikan sebuah kontribusi dan wahan pembelajaran dalam peningkatan pengetahuan mengenai pemanfaatan oasis basah sebagai bahan pengganti media konvensional yang lebih praktis dan efisien pada pencangkokan tanaman mangga dan dapat diimplementasikan dalam penyelenggaraan kegiatan praktikum dasar-dasar agronomi serta perbanyakan tanaman di laboratorium tanaman.

Mengingat beragamnya media yang dapat digunakan sebagai media pertumbuhan tanaman, maka sangat diperlukan kajian dan eksperimen lanjutan agar mendapatkan media tanam yang paling cocok, efektif dan efisien pada pencangkokan tanaman mangga, sehingga akan dapat lebih meningkatkan persentase keberhasilan dalam pencangkokan tanaman khususnya tanaman mangga.

\section{DAFTAR PUSTAKA}

Astutik. 2008. Uji Beberapa Teknik Grafting Mangga Varietas Gadung. Buana Sains. 8(2): 127-130.

Bahri, S. 1999. Bercocok Tanam Tanaman Perkebunan Tahunan. Gajah Mada University Press: Yogyakarta.

Gardner, F. P., R. B. Pearce, dan R. L. Metchell. 1991. Fisiologi Tanaman Budidaya. Universitas Indonesia Press: Jakarta.

Hendrata, R., dan Sutardi, 2010. Evaluasi Media dan Frekuensi Penyiraman terhadap Pertumbuhan Bibit Kakao ( Theobroma cacao L). $J$. Agrovigor. 3(1): 2-4.

Kuswandi. http://balitbu.litbang.deptan.go.id/in 
d/index.php/ hasil penelitianmainmenu-46/ inovasi-teknologi/

16-penelitian pengkajian 2/545. [Diakses 15 Oktober 2018].

Prameswari, Z, K., Sri T, dan Sriyanto W. 2014. Pengaruh Macam Media dan
Zat Pengatur Tumbuh Terhadap Keberhasilan Cangkok Sawo (Manilkara zapota (L.) van Royen) pada Musim Penghujan. Vegetalika. 3(4): 107-118. 